\title{
Technology for the Production of Environment Friendly Tableware
}

\author{
Jüri OLT ${ }^{1 *}$, Viacheslav V. MAKSAROV ${ }^{2}$, Kaarel SOOTS 3 , Tõnu LEEMET ${ }^{4}$ \\ ${ }^{1,3,4}$ Estonian University of Life Sciences, Institute of Technology, 56 F.R.Kreutzwaldi Str., \\ 51006 Tartu, Estonia \\ ${ }^{2}$ Saint-Petersburg Mining University, Department of Mechanical Engineering, 21 Line, \\ St. Petersburg, Russia
}

\begin{abstract}
From the point of view of environmental protection, it is reasonable to stop using disposable tableware that has been made from polluting plastics and to start using biodegradable and compostable products. Biodegradable and compostable tableware is significantly more environment and nature friendly than disposable plastic tableware and drinkware. The by-products (mostly bran) from the milling of wheat, corn and rice and palm leaves are used for the production of tableware. In the Baltic States, including Estonia, it is reasonable to use wheat bran, rye bran and buckwheat bran and the mixtures of these brans. The aim of this research was to provide the technical and technological know-how for the production of environment friendly disposable tableware and to verify the suitability of the new technological means. In order to achieve the aim, a punch and a die were modelled to produce disposable plates with desired parameters, materials and work modes for the material were chosen and, thereafter, the plates were produced from bran using a physical punch and die and using a suitable moulding mode or temperature and compression duration and using prescribed compressive forces. The mechanical properties like density and flexural strength of the moulded plates were determined.
\end{abstract}

Keywords - Biodegradable and compostable tableware; Bran plate; Cutting treatment; Die; Eco-design; Punch

\begin{tabular}{|lll|}
\hline Nomenclature & & \\
$\rho$ & Density of the plate & $\mathrm{g} \mathrm{mm}^{-3}$ \\
$\sigma_{\mathrm{c}}$ & Compressive stress & $\mathrm{MPa}$ \\
$\delta_{\mathrm{fm}}$ & Flexural strength & $\mathrm{N} \mathrm{mm}^{-2}$ \\
$D_{\mathrm{p}}$ & Diameter of the plate & $\mathrm{mm}$ \\
$F$ & Compressive force & $\mathrm{kN}(\mathrm{ft})$ \\
$R_{\mathrm{m}}$ & Tensile strength & $\mathrm{MPa}$ \\
$V$ & Volume of the plate & $\mathrm{mm}^{3}$ \\
$b_{\mathrm{p}}$ & Thickness of the plate & $\mathrm{mm}$ \\
$k_{\mathrm{s}}$ & Form factor & - \\
$m$ & Mass & $\mathrm{g}$ \\
\hline
\end{tabular}

* Corresponding author.

E-mail address: jyri.olt@emu.ee 


\section{INTRODUCTION}

During the 1950s - a period of rapid development for the oil industry - plastic gradually became a vital material for the support of modern life. The introduction of plastic products increased comfort, but also resulted in a vast and catastrophic phenomenon called 'white pollution'. This phenomenon has become an enormous problem for the modern world. 'White pollution' refers to waste that is generated by the use of plastic products of various types. These plastic products are produced from polystyrene, polypropylene, PVS, and other polymers.

We are living in an era of mindless overproduction and overconsumption. Every year, the habited areas release about 8 million tons of plastic waste into bodies of water and, thereafter, the oceans [1]-[3]. The main polluters of the oceans include China, India, Indonesia, the Philippines, Thailand, Sri Lanka, Vietnam and Bangladesh [4]. These countries can be characterised by relatively undeveloped waste handling systems. However, the waste problems are topical not only in these countries, but also in Europe and America. Some countries do not use waste containers for collecting ordinary household waste, not to mention the lack of containers for various types of waste. In addition to the packaging that pollute the living environment (e.g., packaging of chips and sweets), packaging of various beverages (e.g., bottles), filtered tobacco products (e.g., cigarette stubs), balloon sticks, drinking straws, plastic cotton buds and plastic bags, also disposable tableware (cups with various sizes, plates, forks, knives, spoons, skewers) constitute a significant amount of the waste. Such tableware does not decompose when it reaches natural environment; it becomes a source of pollution.

However, not all countries act irresponsibly. Many developed countries have been designing and organising waste management [5] for a longer or shorter period of time, taking various measures to improve the situation and, fortunately, this trend is developing further.

The consumption of disposable plastic tableware increases drastically in the summer, especially during the high season of picnics and barbecues. At the same time, environment-friendly biodegradable tableware has become commercially available, which does not pollute when it reaches the environment; however, the price is higher than that of plastic tableware.

Consumers have begun using alternative biodegradable tableware. Here it must be noted that they may not be completely degradable in nature as they contain microplastics [6]-[8]. Biodegradability means that the material is capable of undergoing aerobic and anaerobic degradation which results in the formation of $\mathrm{CO}_{2}, \mathrm{H}_{2} \mathrm{O}$, methane, biomass and mineral salts. Biodegradable material may not be compostable [9]-[12]. The composting process consists of the decomposing of organic waste by the microbes, i.e., the production of compost. A test performed by the authors of this article showed that all of the 10 test bodies moulded from rye bran, wheat bran and oat bran composted completely within 48 days and left no hazardous residues [13].

Therefore, compostable products, tableware and drinkware are the most nature-friendly ones. Some authors [14]-[16] claim that the use of biodegradable and compostable tableware will reduce ecological footprint. Such products may be produced from the agricultural by-products, namely the by-products of post-harvest processing, which are of natural origin and probably will decompose completely in nature without polluting it. These by-products may include the bran and chaff of cereals, corn or rice, but also straws [17], [18] and tree leaves. For example, about 100000 tons of cereals are milled annually in Estonia. The milling of cereals results in $22 \pm 2 \%$ or 20000-24 000 tons of bran. A portion of this amount can be the potential raw material for compostable tableware. 
The price of bran depends on the market price of cereals, which, reputedly, is a value changing in time and amounts to $60-70 \%$ of the price of cereals, which means that the price of the raw materials of compostable tableware is relatively higher than the price of the raw materials of plastic and cardboard plates and, therefore, the retail price of the bran tableware shall be higher than the price of plastic or cardboard tableware.

Compostable tableware is mostly produced by compressive processing and the stages of its life cycle have been given in Fig. 1.

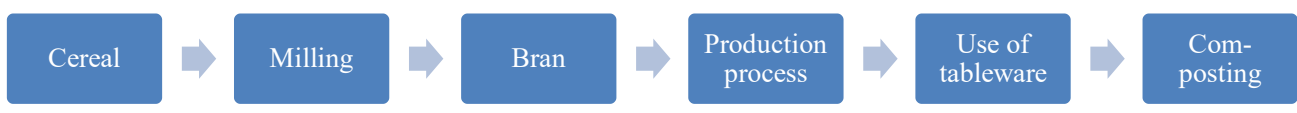

Fig. 1. Lifecycle of compostable tableware [19].

The compressing of the by-products of cereals involves the following processes: pressure is applied to the compressible material and the temperature of the compressible material is raised to a predetermined level, temperature and pressure break the plant's ligneous cell structure, whereby the heat softens the lignin in the material and lignin bonds together the loose particles of the compressible material [19], [20].

The by-products of cereals are what are known as lignocellulose materials which contain neutral fibres (cellulose, hemicellulose, and lignin) [21]. Lignin is the component that binds together all the other components of the material during compression. The difference in lignin content in brans and straws, which can also be used as a raw material for the production of tableware, can be explained by the fact that bran contains starch and, therefore, has a lower lignin content in comparison to straw. Sources [22] claim that potatoes, including potato residues and potato peels, can be used in the production of biodegradable and compostable products. As potato is a material that is quite distinct from cereals and contains mostly starch, the production technology that is used to process it is completely different and will not be discussed in this article.

The introduction of compostable products, including tableware, is feasible only if their mechanical properties are comparable to the mechanical properties of disposable tableware made from cardboard and plastic. The flexural strength of the material suitable for the production of compostable tableware must be at least equal to the flexural strength of plates made from cardboard, which is $\delta_{\mathrm{fm}}=9.98 \mathrm{~N} \mathrm{~mm}^{-2}$ [19].

A compostable tableware production technology contains the following steps: bran with fraction $0.01-2.80 \mathrm{~mm}$ and moisture content of at least $14 \%$ are mixed; then measured into a moulding, which contains a die and a punch and whose temperature is $120^{\circ} \mathrm{C}$ and which is used to compress the material up to the compressive stress of $10 \mathrm{MPa}$; the compression results in a product with the density of 1.1-1.4 $\mathrm{g} \mathrm{cm}^{-3}$ [19].

In order to call the tableware completely compostable, it must meet the requirements [23], [24]-[26]. The standards require that biodegradable/compostable products must degrade completely in the composting environment within a certain time and they are not allowed to leave any hazardous residue.

The aim of this research was to provide the technical and technological know-how for the production of environment friendly disposable tableware and to verify the suitability of the new technological means. 


\section{MATERiALS AND MethodS}

\subsection{Shape of the Plate's Moulding and Modelling}

The bran plate was modelled as three-dimensional with a flat bottom, conical sides and horizontal edges (Fig. 2). The resulting parameters are the plate's diameter $D_{\mathrm{p}}$, height of the side $h$ and wall thickness $b$, whereat $b=$ const. The conical surface of the side is also used for improved centering of the punch and die during compressing.

The geometrical parameters of the plates discussed in this article have been given in Fig. 2. The wall thickness of all the plates with various diameters is $b=2.5 \mathrm{~mm}$.

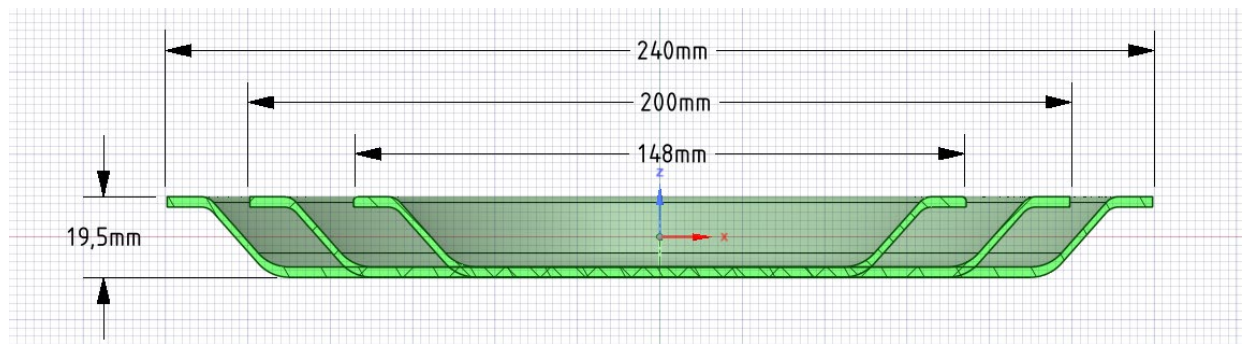

Fig. 2. Model for determining the volume of plates with various diameters (see Table 1).

The moulding used for compressing the plate was modelled in two parts - the upper and the lower part or the punch 1 and the die 2 (Fig. 3).

The edge of the punch is equipped with vertical clearance of edge which enables the steam accumulating during compressing and excess material to escape the moulding.

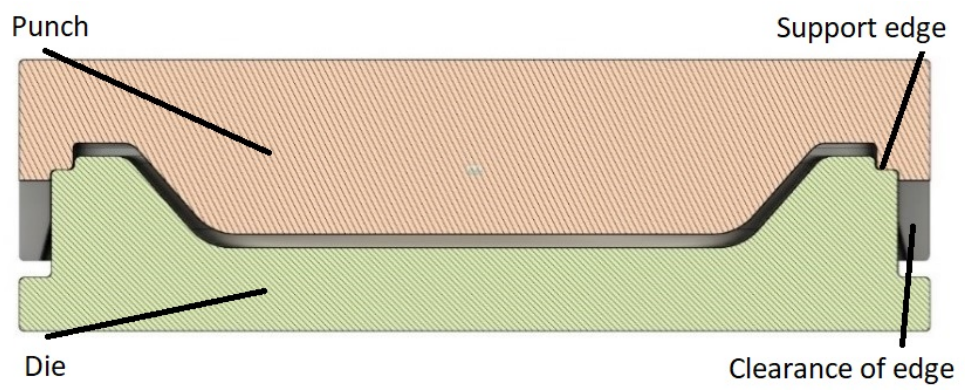

Fig. 3. Cross-section of the moulding's model.

The thickness of the plate's bottom, side and edge is uniform or $b_{\mathrm{p}}=2.5 \mathrm{~mm}$. In order to ensure the uniform thickness of the plate, the moulding is equipped with a support edge, which enables the punch to lean on the die in the final stage of the compressing (Fig. 3). The purpose of the supporting collar is to close the compressing room and to give a finish to the horizontal edge.

The compressible material can be dosed into the die based on mass or volume by using a weightbased or volume-based doser for dosing the material.

Table 1 shows the dosing amounts of raw material necessary for the production of plates with thickness $b_{\mathrm{p}}=2.5 \mathrm{~mm}$. The amount of mass to be dosed can be found from Eq. (1). 


$$
m=\rho \cdot V,
$$

where $\rho$ is the density of the plate and $V$ is the volume of the plate and

$$
V=V_{\mathrm{b}}+V_{\mathrm{s}}+V_{\mathrm{e}},
$$

where

$V_{\mathrm{b}}$ - volume of the bottom;

$V_{\mathrm{s}}$ - volume of the side;

$V_{\mathrm{e}}$ - volume of the edge.

Table 1. Dosage Amounts of Source Materials for the Production of the Plate

\begin{tabular}{lllll}
\hline No. & Plate's diameter, $\mathbf{m m}$ & Plate's volume, $\mathbf{~ m m}^{\mathbf{3}}$ & $\begin{array}{l}\text { Bulk material's } \\
\text { volume, } \mathbf{~ m m}^{\mathbf{3}}\end{array}$ & $\begin{array}{l}\text { Source material's } \\
\text { mass, } \mathbf{g} \text { (rye bran) }\end{array}$ \\
\hline 1 & 148.0 & 44077.0 & 95206.3 & 13.18 \\
2 & 200.0 & 78540.0 & 169646.4 & 23.48 \\
3 & 240.0 & 113097.0 & 244289.5 & 33.82 \\
\hline
\end{tabular}

It must be considered that different barns have different densities (Table 2); the smaller the bulk density of a barn, the more it can be compressed. The volume of bulk material dosed using a volume-based doser is from 1.9 to 2.2 times greater than the volume of the plate to be compressed.

TABLE 2. BRANS BULK DENSITIES

\begin{tabular}{llc}
\hline No. & Material & Bulk density $\mathbf{g ~ c m}^{-3}$ \\
\hline 1 & Wheat bran & $0.183 \pm 0.002$ \\
2 & Oat bran & $0.464 \pm 0.004$ \\
3 & Buckwheat bran & $0.335 \pm 0.003$ \\
4 & Buckwheat hulls & $0.171 \pm 0.004$ \\
5 & Rye bran & $0.299 \pm 0.003$ \\
\hline
\end{tabular}

A hydraulic press was used as the power unit for the compressing of plates.

The modes for producing plates from rye bran were the following:

1. Temperature $T=200{ }^{\circ} \mathrm{C}$ (melting temperature of the lignin).

2. It is generally known that unit pressure $\sigma_{\mathrm{c}}$ is proportional to compressive force $F$ and inversely proportional to cross-section $S$, or

$$
\sigma_{\mathrm{c}}=\frac{F}{S},
$$

taking into account that the cross-section of the plate is $S=\pi \cdot D_{\mathrm{p}}{ }^{2} / 4$, compressive force can be determined as follows

$$
F=\frac{1}{4} \pi \cdot D_{\mathrm{p}}^{2} \cdot \sigma_{\mathrm{c}} \cdot k_{\mathrm{S}}
$$

where $k_{\mathrm{s}}$ is the form factor with numeric value dependent on the shape and height of the moulding.

Considering that compressive stress $\sigma_{\mathrm{c}}=10 \mathrm{MPa}$ and form factor is $k_{\mathrm{s}}=2$ [19], we can determine the compressive forces necessary for the compressing of plates with various diameters (Table 3 ). 
TABLE 3. COMPRESSIVE ForCE F NECESSARY FOR THE COMPRESSING OF PlATES

\begin{tabular}{lll}
\hline No. & Diameter $\boldsymbol{D}$ of the plate, $\mathbf{m m}$ & Compressive force $\boldsymbol{F}, \mathbf{k N}$ (tf) \\
\hline 1 & 148 & $353,2(36.0)$ \\
2 & 200 & $627.8(64.0)$ \\
3 & 240 & $902.5(92.0)$ \\
\hline
\end{tabular}

The compressive force was applied for 3 seconds and the stationary application of the compressive force was $t=90 \mathrm{~s}$.

\subsection{Choice of Material for the Production of the Punch and Die}

As the compressing of the plate is performed at an increased temperature mode, then it is reasonable to choose the heat-resistant steel alloy [27] as a material for the punch and die. The characteristics of the material are the following: re-melted stainless steel Corrax (modified AISI 420). Corrax has a carbon content of $0.03 \%$ and a chromium content of $12.0 \%$, it has a high tensile strength of $R_{\mathrm{m}}=1200 \mathrm{MPa}$ at $200{ }^{\circ} \mathrm{C}$ and a small thermal expansion coefficient of 10.6 from 20 to $45200{ }^{\circ} \mathrm{C}$ [28].

\subsection{Tensile and Flexural Strength}

A three-point flexural test according to the standard ISO 178:2010 [29] was performed to measure the mechanical properties of tableware. Test bodies or compacts were made of studied materials to perform the flexural strength test. An Instron 5969 instrument was used to carry out the flexural strength test. The test bodies were placed on two roller-shaped supports with their centres positioned $L=34 \mathrm{~mm}$ apart, and with a load subsequently being applied to the central part of the test body from the top to the bottom using a roller-shaped element. The radius of the supports and roller applying the load was $5 \mathrm{~mm}$. The load was applied until the test body broke, following which the force necessary to achieve such a break was measured. The measuring range for the force sensor was up to $1 \mathrm{~N}$. The force sensor was calibrated before the tests using the appropriate software. An electronic micrometer with a resolution of $0.0001 \mathrm{~mm}$ was used to measure the thickness of the test bodies.

The authors of this article consider the three-point flexural test similar to real life loads which are applied to tableware upon using it. The test scheme has been shown in Fig. 4 and technical specification in Table 4.

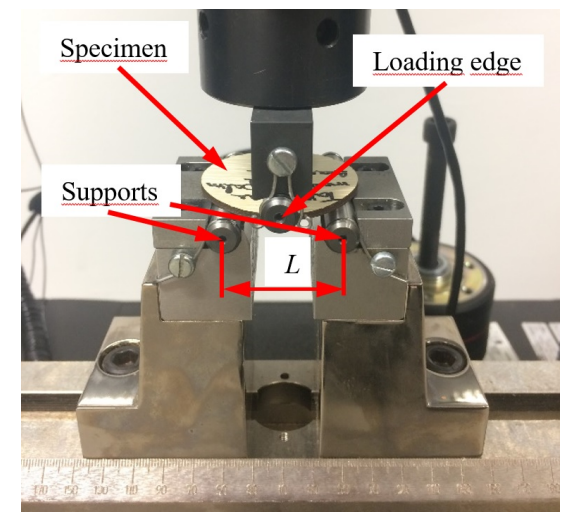

Fig. 4. Test scheme for a three-point flexural test [19]. 
Technical specifications of the flexural tests are given in Table 4.

TABLE 4. TEChNICAL SPECIFICATIONS OF THE FlEXURAL TESTS

\begin{tabular}{ll}
\hline Test device & Instron $\mathbf{5 9 6 9}$ \\
\hline Load cell & $1 \mathrm{kN}$ \\
Span between specimen supports $L$ & $34 \mathrm{~mm}$ \\
Test speed $v$ & $1 \mathrm{~mm} \mathrm{m^{-1 }}$ \\
Radius of the loading edge $R_{l}$ & $5 \mathrm{~mm}$ \\
Radius of the supports $R_{2}$ & $5 \mathrm{~mm}$ \\
Measuring instrument for geometric parameters & Micrometer with a resolution of $0.001 \mathrm{~mm}$ \\
Shape and dimensions of the specimens & Round plate, diameter $50 \mathrm{~mm}$, thickness as it was \\
\hline
\end{tabular}

\section{RESULTS AND DISCUSSION}

\subsection{Manufacturing of the Die and Punch}

The treatment modes of the parts of the moulding have been presented in Table 5.

TABle 5. TReatment Modes of the Milling

\begin{tabular}{lccc}
\hline Cutting data parameters & Rough milling & Fine milling & End milling \\
\hline Cutting speed $\left[\mathrm{m} \mathrm{min}^{-1}\right]$ & 78.0 & 104.0 & 70.0 \\
Feed $\left[\mathrm{mm} \mathrm{tooth}^{-1}\right]$ & 0.3 & 0.1 & 0.06 \\
Depth of cut $[\mathrm{mm}]$ & 4.0 & 1.0 & - \\
Carbide designation ISO & P30 & P20 & K10 \\
\hline
\end{tabular}

The punch and the die were manufactured on the CNC milling machine Haas Super Mini Mill. The physical die and punch and are shown in Fig. 5.

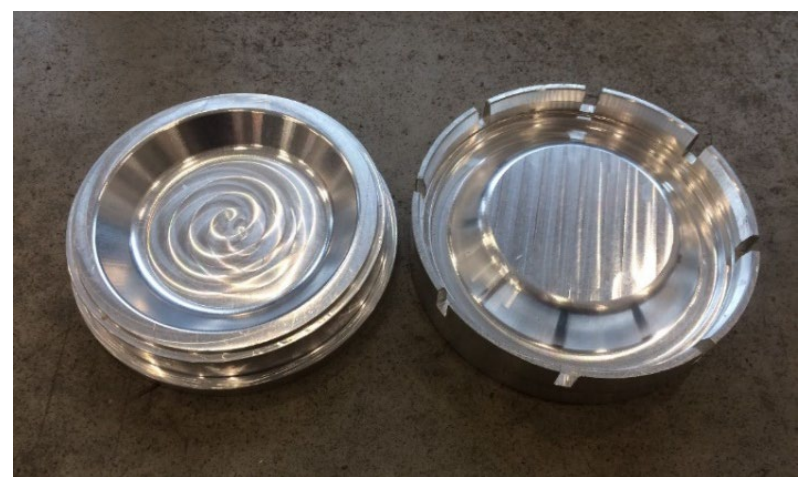

Fig. 5. Die (on the left) and punch (on the right) produced for the compressing of plates.

\subsection{Compressing of the Plates}

The material to be compressed, i.e., rye bran was procured from the cereal mill of Tartu Mill AS. The fractional composition of bran remained in the range of 0.01-2.8 $\mathrm{mm}$. 


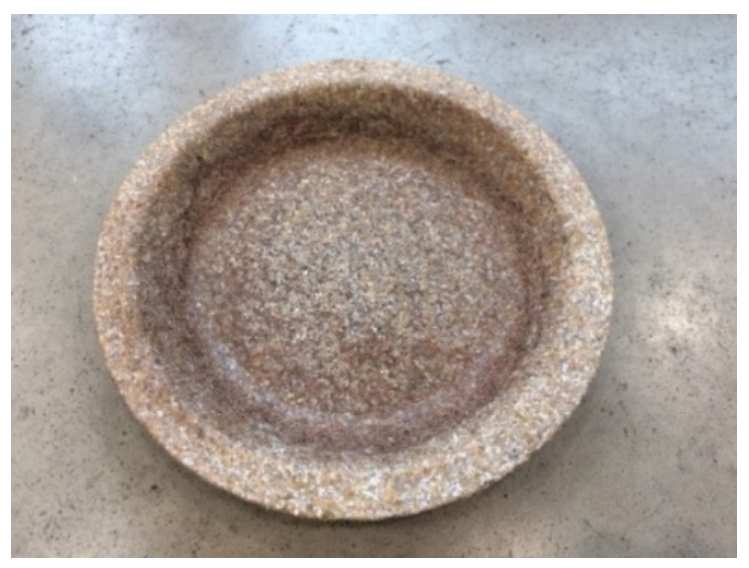

Fig. 6. Prototype of a plate made from rye bran.

The unit pressure of the hydraulic press was $14.7 \mathrm{~N} \mathrm{~mm}^{-2}$ during the application of the $36 \mathrm{tf}$ load for the moulding of the plate. Fig. 6 shows a plate made of rye bran using the following work mode: compressive force $36 \mathrm{tf}$, duration of the load $60 \mathrm{~s}$, duration of forming $90 \mathrm{~s}$ without a load, measured amount of bran $80 \mathrm{~g}$, temperature $200{ }^{\circ} \mathrm{C}$.

In addition to the production mode suitable for tableware made from bran and the recipe, the surface treatment of the tableware should be addressed to ensure quality. This, however, is a completely separate topic.

\subsection{Flexural strength of plates}

Compacts with the following diameters were cut with a laser to perform the flexural strength test and to determine density: diameter $D_{\mathrm{p}}=50 \mathrm{~mm}$, thickness $b_{\mathrm{p}}=2.5 \mathrm{~mm}$. Table 6 presents the data on various brans and their mixtures obtained from tests of mechanical properties.

TABle 6. Flexural Strength of Test Bodies of Plates Made from Bran

\begin{tabular}{llll}
\hline Material & Flexural strength, $\mathbf{N ~ m m}^{-2}$ & $\begin{array}{l}\text { Standard } \\
\text { deviation }\end{array}$ & Standard error \\
\hline Rye bran & 14.61 & 1.07 & 0.62 \\
Wheat bran & 14.24 & 2.05 & 1.18 \\
Buckwheat bran & 8.43 & 2.74 & 1.58 \\
Buckwheat hulls & 4.63 & 0.44 & 0.26 \\
Rye and wheat bran (50:50 \%) & 12.18 & 1.99 & 0.99 \\
Rye and buckwheat bran (50:50 \%) & 16.50 & 0.43 & 0.25 \\
Wheat and buckwheat bran (50:50 \%) & 14.69 & 3.50 & 2.02 \\
Rye bran and buckwheat hulls (50:50 \%) & 12.08 & 1.87 & 1.08 \\
\hline
\end{tabular}

All materials listed in Table 6 which have a flexural strength greater than $10 \mathrm{~N} / \mathrm{mm}^{2}$ are suitable for the production of disposable compostable plates. The flexural strength of the test bodies that were compressed and cut from buckwheat bran and hulls was between $4.63-8.43 \mathrm{~N} / \mathrm{mm}^{2}$, which is a smaller figure than the prescribed flexural strength with the result. Therefore, authors cannot 
recommend the use of these materials for the production of tableware; however, these materials are suitable in mixtures with bran of other cereal.

The densities of test bodies remained in the range of $1.1-1.2 \mathrm{~g} \mathrm{~cm}^{-3}$.

\section{Conclusion}

Compostable tableware can be produced from the by-products of the milling of cereals and, for the most part, using compression. The results of this study showed that, in addition to bran that comes from wheat, rice, and corn that is already acknowledged in the available sources, tableware can be produced from bran that is produced from other cereals, such as rye and buckwheat bran and mixtures of different brans. This significantly widens the selection of raw materials for biodegradable and compostable tableware.

The test works of this research showed that the flexural strengths of test bodies made from rye bran and buckwheat bran slightly exceeded those made of rye bran and wheat bran and other mixtures of brans, which remained in the range of $12.0-16.5 \mathrm{~N} \mathrm{~mm}^{-2}$. Therefore, these materials are suitable for the production of environment friendly tableware. Only the plates compressed from buckwheat bran and hulls had a flexural strength of below $10 \mathrm{~N} \mathrm{~mm}^{-2}$ and, therefore, these materials are separately not suitable for the production of tableware; however, they are suitable in mixtures with other cereal brans. The density of the compressed plates remained in the range of $1.1-1.2 \mathrm{~g} \mathrm{~cm}^{-3}$. In order to reduce the cost price of production, the recipe may include ground cereal straws and chaff, which are also lignocellulose biological materials and compostable.

The long-term aim of this project is to design the technology for the production of biodegradable and compostable tableware, drinkware and packaging with various sizes, to organise production tests and to specify work modes. The designing of the production technology must also address the surface treatment of the tableware. The details of the new automated rotary-type production complex that is being designed contain elements of intellectual property; therefore, its design and technological details will be discussed in further articles.

\section{REFERENCES}

[1] Jambeck J. R., Geyer R., Wilcox C., Siegler T. R., Perryman M., Andrady A., Narayan R., \& Law K. L. Plastic waste inputs from land into the ocean. Science 2015:347.

[2] Macrae F. Eight million tons of plastic is dumped at sea each year... that's five whole bags-full for every foot of the world's coastline. [Online]. [Accessed 04.02.2020]. Available: https://www.dailymail.co.uk/sciencetech/article2951256/Study-World-dumps-8-8-million-tons-plastics-oceans.html

[3] Tullo A. H. Fighting ocean plastics at the source. Chemical \& Engineering news 2018:96(16):28-34. https://doi.org/10.1021/cen-09616-cover1

[4] Walther B. A., Kunz A., \& Hu C-S. Type and quantity of coastal debris pollution in Taiwan: A 12-year nationwide assessment using citizen science data. Marine Pollution Bulletin 2018:135:862-872. https://doi.org/10.1016/j.marpolbul.2018.08.025

[5] Kubule A., Klavenieks K., Veseree R., \& Blumberga D. Towards Efficient Waste Management in Latvia: An Empirical Assessment of Waste Composition. Environment and Climate Technologies 2019:23(2):114-120. https://doi.org/10.2478/rtuect-2019-0059

[6] Shah A. A., Abdul F. H., \& Ahmed H. S. Biological degradation of plastics: A comprehensive review. Biotechnology Advances 2008:26(3):246-265. https://doi.org/10.1016/j.biotechadv.2007.12.005

[7] Siracusa V., Rocculi P., Romani S., \& Rosa M. D. Biodegradable polymers for food packaging: a review. Trends in Food Science \& Technology 2008:19:634-643. https://doi.org/10.1016/j.tifs.2008.07.003

[8] Vaverkova M., Adamcová D., \& Zloch J. How do degradable/biodegradable plastic materials decompose in home composting environment? Journal of Ecological Engineering 2014:15(4):82-89. https://doi.org/10.12911/22998993.1125461 
[9] Song J. H., Murphy R. J., Narayn R., \& Davies G. B. H. Biodegradable and compostable alternatives to conventional plastics. Philosophical Transactions of the Royal Society B 2009:364:2127-2139. https://doi.org/10.1098/rstb.2008.0289

[10] Gurunathan T., Mohanty S., \& Nayak K. S. A review of the recent developments in biocomposites based on natural fibres and their application perspectives. Composites Part A: Applied Science and Manufacturing 2015:77:1-25. https://doi.org/10.1016/j.compositesa.2015.06.007

[11] Elanchezhian C., Ramnath B. V., Ramakrishnan G., Rajendrakumar M., Naveenkumar V., \& Saravanakumar M. K. Review on mechanical properties of natural fiber composites. In Proceedings of International Conference on Materials, Minerals and Energy (PMME) 2018:5(1):1785-1790. https://doi.org/10.1016/j.matpr.2017.11.276

[12] Silva N., \& Blumberga D. Why Biopolymer Packaging Materials are Better. Environmental and Climate Technologies 2019:23(2):366-384. https://doi.org/10.2478/rtuect-2019-0074

[13] Olt J., Soots K., Olt A., \& Rooni V. Exploration of the possibilities for the production of tableware from the bran of various cereals. Proceedings of the 9th International Scientific Conference Rural Development, 2019. http://doi.org/10.15544/RD.2019.020.

[14] Satyanarayana K. G., Arizaga G. G. C., \& Wypych F. Biodegradable composites based on lignocellulosic fibers - An overview. Progress in Polymer Science 2009:34(9):982-1021. https://doi.org/10.1016/j.progpolymsci.2008.12.002

[15] Fieschi M., \& Pretato U. Role of compostable tableware in food service and waste management. A life cycle assessment study. Waste Management 2018:73:14-25. https://doi.org/10.1016/j.wasman.2017.11.036

[16] Willett K., \& Howell B. Using local invasive species and flora to manufacture collagen based biodegradable plastic tableware. In Proceedings of the $21^{\text {st }}$ International Conference on Engineering Design (ICED17), Vancouver, Canada, 2017.

[17] Alun N., Sun Z. H., Jing Q. R., Hu D. R., \& Yang C. L. Study of microstructure and dynamic mechanical analysis of biodegradable tableware produced with corn straw. Advanced Materials Research 2012:380:160-163. https://doi.org/10.4028/www.scientific.net/AMR.380.160

[18] Liu J., Jia C., \& He C. Rice straw and cornstarch biodegradable composites. AASRI Procedia 2012:3:83-88. https://doi.org/10.1016/j.aasri.2012.11.015

[19] Soots K., Olt A., \& Olt J. Manufacturing technology and mechanical properties of biodegradable tableware made from cereal bran. Presented at 47th Int. symposium on Actual Tasks on Agricultural Engineering, Opatija, Croatia, 2019.

[20] Pietsch W. Agglomeration Processes: Phenomena, Technologies, Equipment. Weinheim: Wiley-VCH Verlag, 2002. https://doi.org/10.1002/9783527619801

[21] Raud M., Tutt M., Olt J., \& Kikas T. Dependence of the hydrolysis efficiency on the lignin content in lignocellulosic material. International Journal of Hydrogen Energy 2016:41(37):16338-16343. https://doi.org/10.1016/j.ijhydene.2016.03.190

[22] Priedniece V., Spalvins K., Ivanovs K., Pubule J., \& Blumberga D. Bioproducts from Potatoes: A Review. Environmental and Climate Technologies 2017:21(1):18-27. https://doi.org/10.1515/rtuect-2017-0013

[23] ASTM D6400 - 12. Standard Specification for Labeling of Plastics Designed to be Aerobically Composted in Municipal or Industrial Facilities. [Online]. [Accessed 18.07.2019]. Available: https://www.astm.org/Standards/D6400.htm

[24] ASTM D6868 - 17. Standard Specification for Labeling of End Items that Incorporate Plastics and Polymers as Coatings or Additives with Paper and Other Substrates Designed to be Aerobically Composted in Municipal or Industrial Facilities, 2017. [Online]. [Accessed 1.07.2019]. Available: https://www.astm.org/Standards/D6868.htm

[25] DIN EN 13432. Requirements for packaging recoverable through composting and biodegradation. European Standards. 2000. [Online]. [Accessed 18.07.2019]. Available: https://www.en-standard.eu/din-en-13432-requirements-forpackaging-recoverable-through-composting-and-biodegradation-test-scheme-and-evaluation-criteria-for-the-finalacceptance-of-packaging-english-version-of-din-en13432/?gclid=EAIaIQobChMIi63nsCN3gIViuiaCh0vPgNdEAAYASAAEgJOavD_BwE

[26] ISO 14851:1999. Determination of the ultimate aerobic biodegradability of plastic materials in an aqueous medium -Method by measuring the oxygen demand in a closed respirometer, 1995. (corrected version 2003)

[27] Fischer U., Gomeringer R., Heinzler M., Kilgus R., Näher F., Oesterle S., Paetzold H., \& Stephan A. Mechanical and Metal Trades Handbook. Germany: Verlag Europa Lehrmittel, 2010.

[28] Uddeholm Corrax, Technical data sheet. [Online]. [Accessed 14.02.2020]. Available: https://www.uddeholm.com/files/PB_Uddeholm_corrax_english.pdf

[29] ISO 178:2010. Plastics - Determination of flexural properties. [Online]. [Accessed 14.02.2020]. Available: https://www.iso.org/standard/45091.html 